\title{
Cataract and myotonic dystrophy: the role of molecular diagnosis
}

\author{
W Reardon, J C MacMillan, J Myring, H G Harley, S A Rundle, L Beck, P S Harper, D J Shaw
}

\begin{abstract}
Myotonic dystrophy (dystrophia myotonica), the commonest and most variable of the muscular dystrophies of adult life, has long been known to be associated with cataract, while slit-lamp examination for specific lens opacities has been one of the principal methods of presymptomatic detection of gene carriers. The recent discovery that the myotonic dystrophy mutation is an unstable DNA sequence, composed of varying numbers of CTG triplet repeats, now allows a specific molecular test for this disorder, as well as explaining the phenomenon of anticipation. A series of case reports is presented to illustrate the important practical applications of this development in relation to ophthalmic aspects of the disorder. Reassessment of the specificity of the ophthalmic changes may be required and it will be important for molecular analysis to be used alongside ophthalmic studies, when determining whether family members carry the mutation for myotonic dystrophy.
\end{abstract}

(Brf Ophthalmol 1993; 77: 579-583)

Myotonic dystrophy (dystrophia myotonica, DM), the commonest form of adult muscular dystrophy, ${ }^{1}$ was first recognised in $1909^{23}$; by 1911 Greenfield $^{4}$ had already recognised an association with cataract, while by 1918 Fleischer ${ }^{5}$ had shown that cataract could occur in generations preceding full myotonic dystrophy and that different pedigrees could be connected through individuals affected by cataract alone. He proposed the concept of anticipation, in which clinical features were progressively more serious and of earlier onset in successive generations, with cataract being the initial and mildest feature of the disease, especially in the earlier generations. Fleischer and, later, $\operatorname{Vogt}^{6}$ also recognised the specific nature of the lens changes in the disorder, multicoloured, crystalline, subcapsular opacities being visible with the slit-lamp before any cataract appeared producing visual symptoms.

The highly variable neuromuscular features of myotonic dystrophy, ranging from fatal neonatal disease due to respiratory inadequacy, to minimal myotonia in later life, have caused considerable difficulties in genetic counselling, particularly in the exclusion of the gene in relatives at risk. Slit-lamp examination of the lenses has always been recommended as an essential part of the investigation of such individuals, and most studies have shown a small but definite proportion with specific lens abnormalities who would not otherwise have been recognised. ${ }^{78}$

Over the past 5 years, DNA markers linked to the DM locus have been available, and have allowed a relatively accurate prediction as to the presence or absence of the gene ${ }^{9-11}$; these have not, however, been of use in the absence of an appropriate family structure, which has limited their value.

The recent identification, by ourselves and others, of a specific gene defect in myotonic dystrophy ${ }^{12-14}$ now allows us the possibility of using molecular techniques in the diagnosis of this disorder. The defect is the expansion of an unstable CTG sequence in a gene whose predicted protein product is a member of the protein kinase family, ${ }^{15}$ the degree of expansion of the sequence showing a relation to the clinical features of the disease. ${ }^{16}$ This CTG repeat sequence is located in the $3^{\prime}$ untranslated region of the gene. Normal individuals have up to 30 copies of the repeat but in DM the number ranges from 50 to more than 2000 . We here report our early experience in using this new investigation in the assessment of myotonic dystrophy patients and relatives in whom cataract has been the principal clinical feature, and where lens opacities have been important in diagnostic conclusions.

\section{Methods}

DNA was isolated from peripheral blood lymphocytes with standard techniques and analysed, with two approaches, as described previously. ${ }^{15}{ }^{17}$ Southern blotting, with the DNA probe M10M6 detects fragments of 9 and 10 kilobases $(\mathrm{kb})$ in the normal population when DNA is digested with restriction enzyme EcoR 1 , but in myotonic dystrophy patients expansion of the $10 \mathrm{~kb}$ fragment is seen, giving an alteration in band pattern that is particularly clear with larger expansions. Smaller changes can be detected with the same probe after PstI digestion of the genomic DNA. Polymerase chain reaction (PCR) analysis for the CTG repeat provides a quantitative analysis of the number of repeat sequences, which is suitable for small DNA expansions as these may be difficult to detect by Southern blotting.

\section{CASE 1}

This family came to attention when IV-1 (Fig 1) was born and features of the congenital form of myotonic dystrophy were recognised, with hypotonia, bilateral talipes, feeding problems, and subsequent delayed motor and intellectual development. Examination of the mother (III-4) confirmed the presence of clinical myotonia. Her sisters III-1 and III-6 were likewise found to have clear clinical evidence of myotonic dystrophy and, although III-1 had been attending an infertility clinic for 3 years, the underlying cause of 


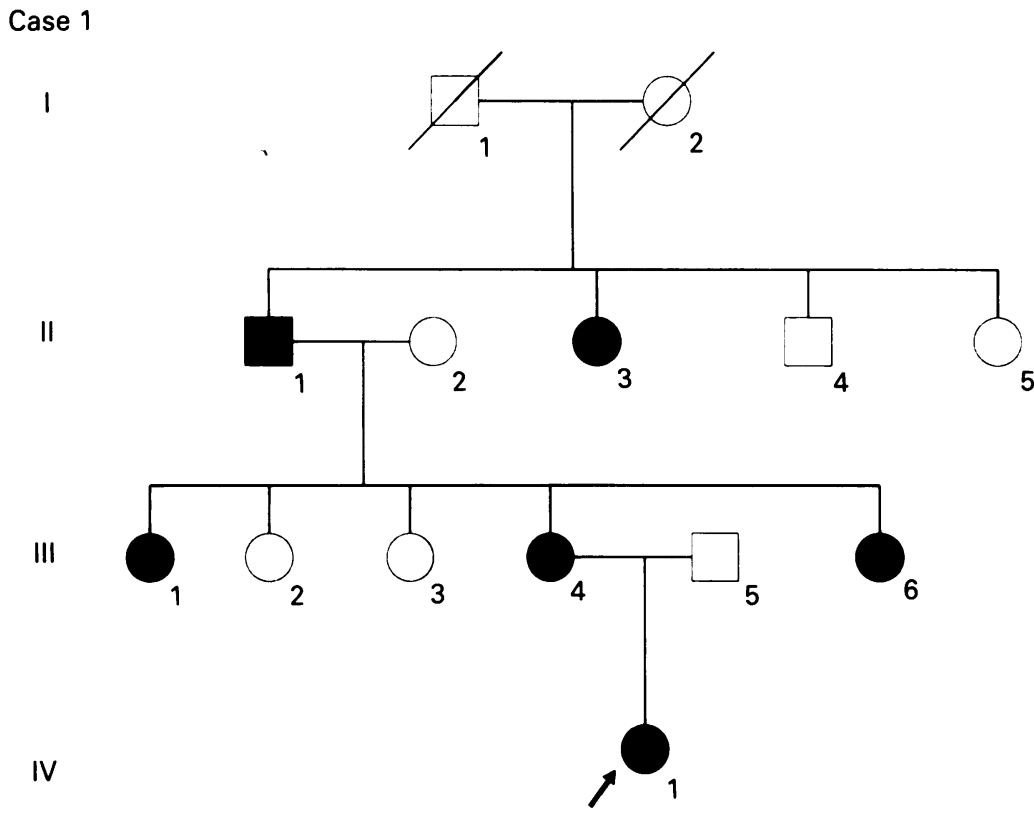

Figure 1 Pedigree for case 1 .

her infertility had not been recognised. Slit-lamp ophthalmic examination in both III-1 and III-6 was normal.

On examination at the age of 70, II-1 was noted to have a long face but there was no evidence of myopathy or of grip or percussion myotonia. He had had bilateral cataract removal aged 51 as had his sister (II-3) who went on to develop symptomatic muscle disease in her $60 \mathrm{~s}$.

Molecular analysis (Fig 2) confirmed that II-1 was the gene carrier; he is heterozygous for the EcoRI polymorphism of M10M6 and shows an expansion of $0.18 \mathrm{~kb}$ in the $10 \mathrm{~kb}$ allele using PCR analysis. His wife is homozygous for the $9 \mathrm{~kb}$ allele and there is a progressive enlargement of the paternal $10 \mathrm{~kb}$ allele as it is transmitted to III-4 and subsequently to IV-1. This intergenerational molecular instability manifests clinically as the anticipation observed in this family and recognised many years ago to be a feature of the disorder.

CASE 2

This 78-year-old man came to our attention when his daughter (II-1, Fig 3) was diagnosed with classic features of myotonic dystrophy, including bilateral posterior polar cataract at the age of 39 years. Her parents were subsequently investigated. The mother (I-2) aged 63, was clinically normal and had a normal EMG. Her slit-lamp examination showed early non-specific lens opacities thought to be age related. The father I-1 aged 73 was clinically normal as was his EMG. Slit-lamp examination showed bilateral subcortical and subcapsular lens opacities with bilateral posterior polar early cataract. Confirmation of the father as the gene carrier required PCR analysis to demonstrate minimal expansion (55 repeats) at the myotonic dystrophy locus. Figure 4 shows the progressive enlargement in the grandpaternal allele as it is transmitted through II-1 to III-1 (he has inherited a normal $10 \mathrm{~kb}$ allele from his father).

\section{CASE 3}

This 70-year-old woman (I-2, Fig 5) came to our attention when her granddaughter (III-4) was recognised to have congenital myotonic dystrophy. Subsequent investigation of generations II and III revealed several other affected members. In attempting to trace the origin of the gene, I-2 was examined. Clinical examination of the neuromuscular system was normal, although diabetes mellitus and rheumatoid arthritis were noted. There was no evidence of myotonia and this was confirmed by negative EMG findings.

Ophthalmic examination by a neurologist was said to show evidence of early cataract but this was attributed to her diabetes and a slit-lamp examination was not performed.

Molecular analysis of her myotonic dystrophy locus has shown the presence of two normal alleles thus excluding her as the origin of the disease in this family.

\section{CASE 4}

This 23-year-old woman (pedigree not shown) was known to be at $50 \%$ risk of having inherited the gene for myotonic dystrophy from her mother who was affected. Clinical examination was normal as were EMG studies. Following the birth of her triplets the patient wished to have them adopted. In view of the family history, the adoption agency asked if the risk to the children could be refined. This necessitated refining the

Case 2

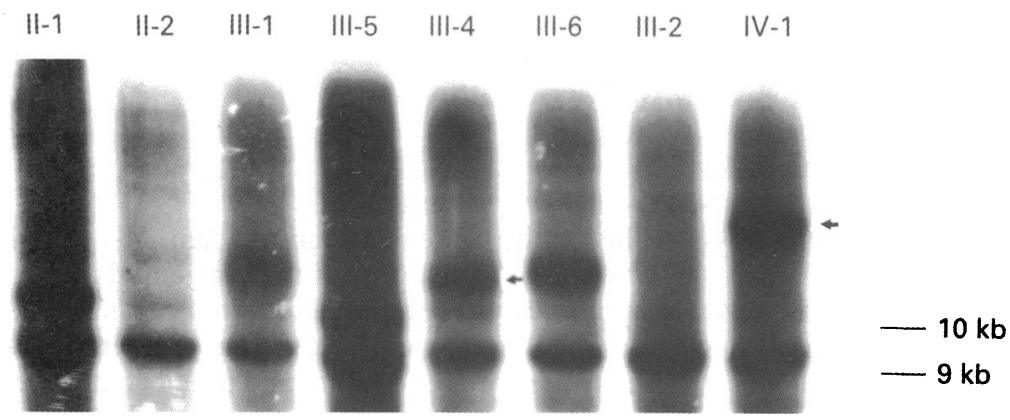

Figure 2 M10M6 EcoR1 analysis of family members from Figure 1. II-1 is heterozygous for the $9 \mathrm{~kb}$ and $10 \mathrm{~kb} E \mathrm{E}$ CoR 1 polymorphisms detected by M10M6. There is the suggestion that the $10 \mathrm{~kb}$ allele is larger than the normal $10 \mathrm{~kb}$ seen in III-5 (unaffected spouse of III-4). This expanded $10 \mathrm{~kb}$ allele progressively enlarges as it is transmitted through III-4 to IV-I. Lanes 2 (II-2) and 7 (III-2) show unaffected family members, while lanes $3(I I I-1)$ and 6 (III-6) show other affected individuals. 
$1-1$

$1-2$

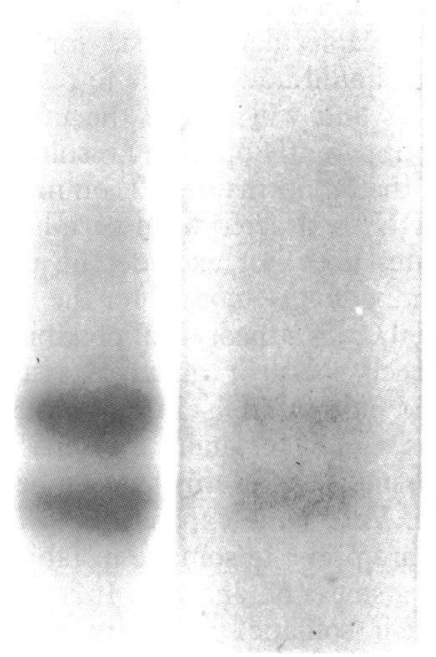

$11-1$

III-1

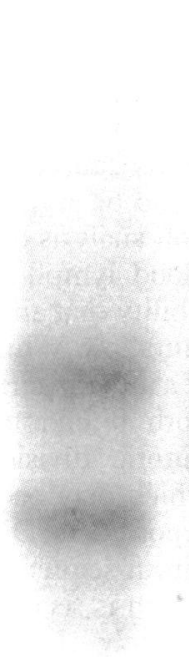

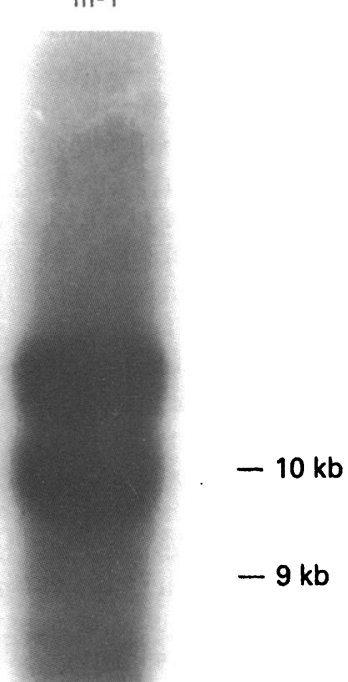

Figure 4 M10M6 EcoRI analysis of family of case 2. It is not possible to identify an expansion in the $10 \mathrm{~kb}$ EcoRI polymorphism seen in I-1 (it was found by PCR analysis) but there is progressive enlargement from II-1 to III-1. III-1 has inherited a normal $10 \mathrm{~kb}$ allele from his unaffected father (who is not shown in this figure).

risk for the mother, who, if shown to be at low risk of having inherited the gene for myotonic dystrophy, would be most unlikely to have transmitted it to her children.

Slit-lamp examination in the proband showed a localised subtle posterior subcapsular opacity bilaterally. Such a lens opacity was felt to be highly unusual in a normal person and it was felt that, although atypical, these lenticular changes might signify the presence of the myotonic dystrophy gene.

Molecular analysis of the myotonic dystrophy locus showed that the expanded allele in her mother was not present in the proband. She was therefore reassured that it was most unlikely that she had inherited the gene for DM.

\section{CASE 5}

This 32-yeàr-old woman (II-2, Fig 6) was known to be at $50 \%$ risk of inheriting the myotonic dystrophy gene as both her father and two brothers were affected with the condition. She

Case 3

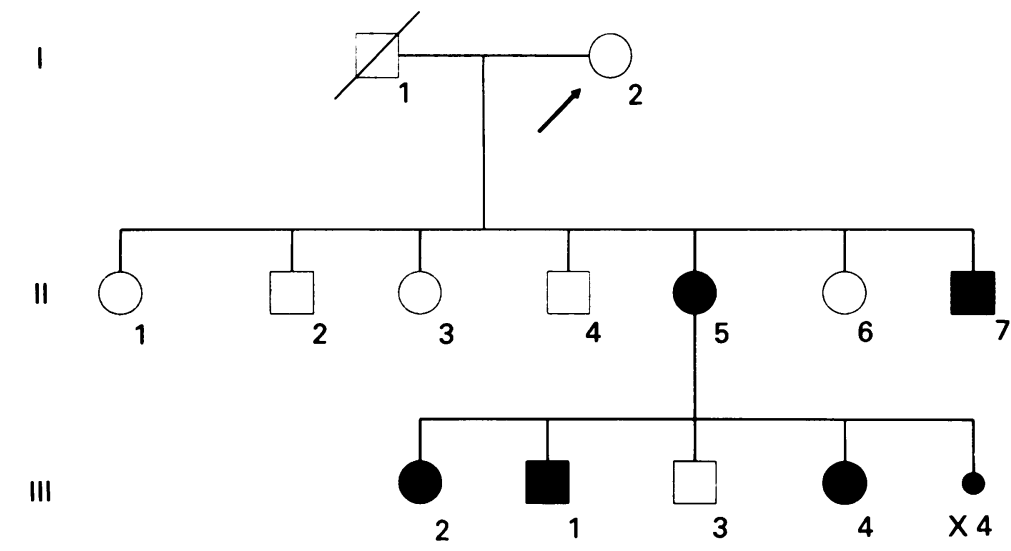

Figure 5 Pedigree for case 3.

Case 5

II

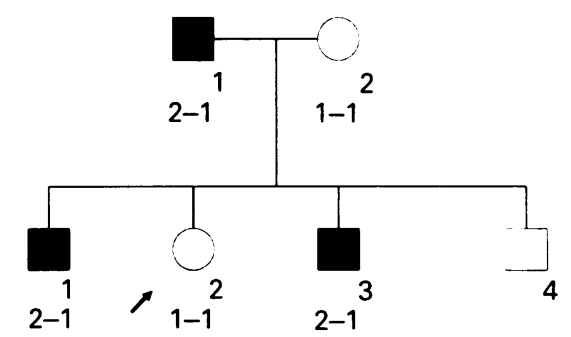

Figure 6 Pedigree for case 5. Typings refer to the BCLS/MIUI and EcorRI polymorphisms. II-2 has inherited, from her affected father, the opposite allele (1) of this closely linked polymorphism to that inherited by her two affected brothers (allele 2).

sought predictive testing before marriage. Clinical and EMG examinations were normal. Slitlamp examination showed no polychromasia but widespread white anterior cortical opacities of the lens were observed bilaterally. These were felt to be abnormal in a patient of this age.

Molecular prediction by the linked DNA probe BCL3 showed her to be at low risk of having inherited the gene for myotonic dystrophy as she had inherited the opposite paternal allele to her affected brothers (see Fig 6). However, as this result was reached using linkage analysis the possibility that a recombination had taken place between the linked probe and the myotonic dystrophy gene could not be discounted. Thus, it was not possible to counsel this woman accurately as to her specific risk for myotonic dystrophy in view of the dichotomy between molecular and ophthalmic findings.

Subsequent analysis for the specific mutation showed no evidence of the expansion associated with myotonic dystrophy, confirming the result based on linkage and indicating that the ophthalmic findings were not related to myotonic dystrophy.

\section{CASE 6}

This 22-year-old woman (pedigree not shown) requested presymptomatic testing for myotonic dystrophy in view of her positive family history of the condition. Her father and two brothers were unequivocally affected. A history of myotonia was not elicited, nor was evidence of myotonia found on clinical or EMG examination. Slit-lamp examination of her lenses demonstrated polychromatic opacities which, in view of her $50 \%$ prior risk for myotonic dystrophy, were felt to be highly suggestive of the condition.

Predictive testing using the tightly linked DNA marker, D10 (estimated error owing to recombination less than $2 \%$ ) showed that she had inherited the opposite paternal allele to her affected brother and, so, appeared to be at low risk. This dichotomy between her perceived high risk on clinical grounds and low risk by the linkage methods has been resolved by confirming that she does not possess an expanded sequence at the myotonic dystrophy locus. As with case 5 , the lens changes are not likely to be related to the disorder, a significant observation since polychromatic opacities have been considered to be specific for myotonic dystrophy. 
CASE 7

This 43-year-old woman presented via the ophthalmology department. She was known to be myopic and had been referred by her optician in view of signs of developing cataracts. Slit-lamp examination showed numerous anterior cortical polychromatic crystals typical of those seen in myotonic dystrophy. There was no personal or family history of muscle weakness or myotonia. Clinical examination of the neuromuscular system was normal and the absence of subclinical myotonia was confirmed by a normal EMG. Examination of her children was also entirely normal. Molecular analysis has subsequently confirmed the absence of an abnormal expansion at the myotonic dystrophy locus and, despite the polychromatic lenticular changes, it has been possible to reassure her that there is no evidence of her being a carrier of the myotonic dystrophy mutation.

\section{Discussion}

The discovery of a specific molecular defect in myotonic dystrophy allows, for the first time, the possibility of an accurate diagnostic test for this disorder, as well as one that can confirm or exclude the presence of the gene in those at risk. The detection of the unstable sequence also explains the long debated phenomenon of anticipation in myotonic dystrophy, ${ }^{18}$ as shown in Figure 1, where the increase in expansion can be seen to correlate with the increasing severity in successive generations. Despite Fleischer's early recognition of this phenomenon in 1918 , it was for many years considered to result from ascertainment bias rather than from true biological variation in the genetic defect. ${ }^{19}$

Since cataract is often the only abnormality in minimally affected members of the older generations of myotonic dystrophy families, considerable diagnostic significance has rested on the interpretation of the ocular findings in such individuals. Cataracts may already be dense or may have been removed when the possibility of myotonic dystrophy is first raised, leaving very real doubts as to their significance. Thus the confirmation of a molecular abnormality, as in cases 1 and 2, is of considerable importance in genetic counselling for younger generations of the family.

Since cataracts in the elderly are so frequent it would seem wise to obtain molecular confirmation before coming to a conclusion on the relation between cataract and myotonic dystrophy in such a situation. This can be done using a blood or mouthwash sample to obtain DNA; in view of the minimal expansion likely in patients with cataract only, it is important that accurate quantitation of the DNA expansion, using PCR based techniques, is undertaken, since Southern blotting (as shown in Fig 1) is less sensitive in the detection of such small changes.

In the studies that have so far compared the use of slit-lamp and EMG investigations in relatives at risk with results of linked DNA markers, ${ }^{2021}$ most cases showed concordance between the results of these two approaches, but there were also instances ${ }^{11}$ where a low risk was predicted by DNA markers but where lens opacities thought to be specific were present, as in case 4 of our series (this individual was reported as case 2 in Reardon et $\left.a l^{\prime \prime}\right)$. Molecular analysis for the specific mutation should now be able to resolve such discrepancies and will relieve the uncertainty caused by apparently opposing results. It could be argued that a 'normal result' on mutation analysis of DNA extracted from peripheral blood lymphocytes does not exclude the possibility that an individual is 'mosaic' for the DM mutation. While there is a theoretical possibility of a mutant germ cell (sperm or egg) giving rise to both mutant and normal cells in subsequent mitotic divisions, with resultant 'mosaicism' which may be tissue specific, this has not been reported in DM. Very large expansions in the repeat sequence are prone to somatic instability which is seen as a smear on analysis. It is most unlikely that such somatic instability would result in reversion to a normal repeat number in any tissue. Reversion to a normal repeat number has, however, been reported as a meiotic event. ${ }^{22}$ O'Hoy et al $^{22}$ describe a possible gene conversion event whereby an individual inherited a paternal myotonin gene with a normal repeat number on the chromosome which in him carried an expanded sequence. In our experience (data not shown) the mutation is present in all tissues sampled from an affected individual.

Patients with myotonic dystrophy are not infrequently first seen by ophthalmologists because of cataract. Most such patients prove, on wider investigation, to show myotonia and other neurological abnormalities, or to have relatives with such involvement. Occasionally, however, an apparent case of 'myotonic cataract' is seen with typical ophthalmic features but with no other evidence of myotonic dystrophy in the patient or in family members. Case 7 in our series illustrates this situation, one which understandably produced considerable concern, and which could not have been fully resolved without the aid of the specific molecular investigation. It thus seems likely that not all cases of early cataract suggestive of myotonic dystrophy will be due to this disorder; study of larger numbers of such cases will be needed before firm conclusions can be reached on the specificity of the ophthalmic findings. We are currently investigating other such cases and are also examining a series of unselected cataract patients to determine whether a significant number of them show the myotonic dystrophy mutation. It is possible that minimal gene carriers may be commoner in the population than has hitherto been recognised.

A final unanswered question relates to how the specific mutation in the myotonic dystrophy gene produces cataract, and why this abnormality should so often occur in patients with small DNA expansions in whom neuromuscular abnormalities are minimal. The predicted protein sequence of the gene shows strong homology with the protein kinase family of enzymes, ${ }^{15}$ but a more precise relationship of the lens disturbance and the molecular defect will require isolation and characterisation of this protein. Since the unstable sequence occurs in the $3^{\prime}$ untranslated region of the gene, it is possible that it exerts its effect indirectly through the DNA expansion, rather than by the production of a structurally 
abnormal protein. It is also possible that the cataract could result from disrupted function of a different part of the gene from that involved in the neuromuscular abnormality, or even from disturbance of an adjacent gene.

The recognition of a specific molecular abnormality in myotonic dystrophy now means that these and other important questions can be addressed, even if they cannot immediately be answered. Meanwhile the discovery provides a test that should be of practical value in resolving the ophthalmic diagnostic problems that are encountered in myotonic dystrophy patients and their relatives.

1 Harper PS. Myotonic dystrophy. 2nd ed. London: Saunders, 1989.

2 Steinhert H. Myopathologische Beitrage 1. Uber das klinische und anatomische Bild des Muskelschwunds der Myotoniker. Dtsch Z Nervenheilkd 1909; 37: 58-104.

3 Batten FE, Gibb HP. Myotonia atrophica. Brain 1909; 32: 187-205.

4 Greenfield JG. Notes on a family of "myotonia atrophica" and early cataract, with a report on an additional case of myotonia atrophica. Rev Neur Psych (Edin) 1911; 9: 169-81

5 Fleischer B. Uber myotonische Dystrophie mit Katarakt, Albrecht von Graefes. Arch Klin Ophthalmol 1918; 96: 91-133.

6 Vogt A. Die Cataract bei myotonische Dystrophie. Schweiz Med Wochenschr 1921; 29: 669-74.

7 Bundey S, Carter CO, Soothill JF. Early recognition of heterozygotes for the gene for dystrophia myotonica. f Neurol Neurosurg Psychiatry 1970; 33: 279-93.

8 Harper PS. Presymptomatic detection and genetic counselling in myotonic dystrophy. Clin Genet 1973; 4: 134-40.

9 Meredith AL, Huson SM, Lunt PW, Sarfarazi M, Harley HG, Brook JD, et al. Application of a closely linked polyBrook JD, et al. Application of a closely linked polymorphism of restriction fragment length to counselling and prenatal testing in families with myotonic dystrophy. BMF
1986; 293: 1353 -6. symptomatic detection and prenatal diagnosis for myotonic dystrophy by means of linked DNA markers. 7 Med Genet 1989; 26: 750-4.

11 Reardon W, Floyd JL, Myring J, Lazarou LP, Meredith AL, Harper PS. Five years experience of predictive testing for myotonic dystrophy using linked DNA markers. $A m \mathcal{F}$ Med Genet 1992; 43: 1006-11.

12 Harley HG, Brook JD, Rundle SA, Crow S, Reardon W, Buckler AJ, et al. Expansion of an unstable DNA region and phenotype variation in myotonic dystrophy. Nature 1992;
355: 547-8.

13 Buxton J, Shelbourne P, Davies J, Jones C, Van Tongeren T, Aslanidis C, et al. Detection of an unstable fragment of DNA specific to individuals with myotonic dystrophy. Nature 1992; 355: 547-8.

14 Aslanidis C, Jansen G, Amemiya C, Shulter G, Mahadevan M, Tsilfidis C, et al. Cloning of the essential myotonic dystrophy region and mapping of the putative defect. Nature 1992; 355 548-51.

15 Brook JD, McCurrach ME, Harley HG, Buckler AJ, Church $\mathrm{D}$, Aburatani $\mathrm{H}$, et al. Molecular basis of myotonic dystrophy. Expansion of a trinucleotide (CTG) repeat at the 3" end of a transcript encoding a protein kinase family member. Cell 1992; 68: 700-808.

16 Harley HG, Rundle SA, MacMillan J, Myning J, Brook JD, Crow S, et al. Variable expansion of an unstable CTG repeat sequence in relation to phenotype in myotonic dystrophy. 17. Am $\mathcal{F}$ Hum Genet 1993 (in press).

17 Reardon W, Harley HG, Brook JD, Rundle SA, Crow S, Harper DS, et al. Minimal expression of myotonic dysHarper DS, et al. Minimal expression of myotonic dyspress).

18 Harper PS, Harley HG, Reardon W, Shaw DJ. Anticipation in myotonic dystrophy: new light on an old problem. Am F Hum Genet 1992; 51: 10-6.

19 Penrose LS. The problem of anticipation in pedigrees of dystrophia myotonica. Ann Eugen 1948; 14: 125-232.

20 Brunner HG, Smeets HJM, Nillesen W, Van Oost BA, Van den Biezenbos JBM, Joosten EMG, et al. Myotonic dystrophy: predictive value of normal results on clinical examination. Brain 1991; 114: 2303-11.

21 Ashizawa T, Heitmankci JF, Liu J, Perryman MB, Epstein HF, Koch DD. Diagnostic value of ophthalmologic findings in myotonic dystrophy: comparison with risks calculated by haplotype analysis of closely linked restriction fragment haplotype analysis of closely linked restriction fragment

length polymorphisms. Am f Med Genet 1992; 42: 55-60.
22 O'Hoy KL, Tsilfidis C, Mahadevan MS, Neville CE, Barceló $\mathrm{J}$, Hunter AGW, et al. Reduction in size of the myotonic dystrophy trinucleotide repeat during transmission. Science 1993; 259: 809-12. 